\title{
In vitro cultivation and temperature-dependent growth of two strains of Spironucleus barkhanus (Diplomonadida: Hexamitidae) from Atlantic salmon Salmo salar and grayling Thymallus thymallus
}

\author{
Erik Sterud* \\ Norwegian College of Veterinary Medicine, PO Box 8146 Dep., N-0033 Oslo, Norway
}

\begin{abstract}
Spironucleus barkhanus from muscle abscesses of farmed Atlantic salmon Salmo salar L. and from the gall bladder of grayling Thymallus thymallus (L.) was cultivated axenically in a medium routinely used for cultivation of the human pathogen Giardia duodenalis. Trophozoites multiplied by binary division, but multinucleated cells $(<10$ nuclei) were frequently observed. Complete cell divisions were never observed in these cells. Both strains grew at all temperatures tested $\left(5,10,15\right.$ and $20^{\circ} \mathrm{C}$ ). However, continuous growth of the salmon strain at $20^{\circ} \mathrm{C}$ was not possible. Growth potential, calculated as minimum generation time, showed relatively small differences both between strains and among temperatures, but the results indicate that the grayling strain had both a slightly higher optimum temperature and a higher upper temperature limit than the salmon strain.
\end{abstract}

KEY WORDS: Farmed salmon Giardia Hexamita Nuclel acid staining - Systemic infection

\section{INTRODUCTION}

Hexamitid flagellates have been associated with significant disease problems in a range of fish species. A catarrhal enteritis is typical in salmonids infected with hexamitids (Moore 1922, Davis 1926, Miura \& Ohsima 1960, Sano 1970, Woo \& Poynton 1995). In ornamental fish these flagellates have been associated with systemic infections and 'hole-in-the-head' disease (Ferguson \& Moccia 1980, Bassleer 1983, Poynton et al. 1995). Poppe et al. (1992) and Poppe \& Mo (1993) described systemic hexamitosis from farmed Atlantic salmon Salmo salar L. in northern Norway, and a similar case was reported from farmed chinook salmon Oncorhynchus tshawytscha in Canada (Kent et al. 1992). These were the first reported cases of systemic infection with hexamitids in salmonid hosts. The fish were severely affected, and in the Norwegian cases, the hexamitid flagellates were abundant in necrotic lesions in the muscles and internal organs. The flagellate, first

•E-mail:erik.sterud@veths.no believed to be Hexamita salmonis Moore, 1922, was described as Spironucleus barkhanus by Sterud et al. (1997), who also found the flagellate in grayling Thymallus thymallus (L.) from southeastern Norway. Much is still to be elucidated about the biology of hexamitids parasitizing fish, including the mechanisms of transmission and disease development. It is believed that in vitro cultivation will be a valuable tool for obtaining flagellates for future experimental studies of these mechanisms. This was suggested by Buchmann \& Uldal (1996) and has already been shown for the related genus Giardia. Trypticase yeast extract iron serum medium (TYI-S-33) (Diamond et al. 1978), as modified by Keister (1983), is now widely used for routine cultivation of Giardia duodenalis for experimental studies. In the present study, the use of Keister's medium for in vitro cultivation of $S$. barkhanus is presented. In addition, the temperature-dependent growth of $S$. barkhanus isolated from sea-ranched Atlantic salmon in subarctic conditions is tested and compared with the same species isolated from grayling in a freshwater, temperate environment. 


\section{MATERIALS AND METHODS}

Isolation of parasites. Spironucleus barkhanus Sterud, Mo \& Poppe, 1997 was isolated from the gall bladder of grayling from the river Glomma in southeastern Norway in October 1994. The fish were caught by angling and kept in river water at $5^{\circ} \mathrm{C}$ until isolation of the parasites. The fish were killed by a sharp blow to the head. There were no signs of disease in live fish or at necropsy. The gall bladder was emptied with a sterile syringe, and the content inoculated into a $15 \mathrm{ml}$ plastic screw-cap culture tube containing $10 \mathrm{ml}$ of the culture medium, at a temperature of $5^{\circ} \mathrm{C}$. Antibiotics were not added. The strain has been deposited at the American Type Culture Collection (ATCC), Rockville, Maryland, USA, and was assigned accession number 50467. S. barkhanus was also isolated from Atlantic salmon with systemic spironucleosis, from a seawater farm in Finnmark county in northern Norway. This strain, obtained directly from a muscle abcess, has also been deposited at ATCC and was assigned accession number 50377 . Both axenized strains were routinely cultivated at $5^{\circ} \mathrm{C}$. Subcultures were made every $14 \mathrm{~d}$ by inoculating $1 \mathrm{ml}$ aliquots into $9 \mathrm{ml}$ fresh medium.

Culture medium. The flagellates were cultivated in Keister's medium (1983) modified by substituting casein digest for trypticase and equine serum for bovine serum. The medium was prepared without cysteine and serum added, and $\mathrm{pH}$ adjusted to 7.1 with $5 \mathrm{M} \mathrm{NaOH}$. The medium was stored frozen at $-20^{\circ} \mathrm{C}$ until needed. When required, the medium was thawed, cysteine and serum added, and the complete medium was filter sterilised.

Light microscopy. Live flagellates were viewed in a Leitz microscope at 100 to $600 \times$ magnification. Fluorescent nucleic acid staining was performed on the grayling strain. Four $\mathrm{ml}$ of flagellate culture was fixed by adding $0.15 \mathrm{ml} 25 \%$ glutaraldehyde. The sample was gently centrifuged and washed twice in medium WC (see Guillard \& Lorenzen 1972). Finally, the flagellates were stained by adding 4'-6-diamidino-2-phenylindole (DAPI) dissolved in distilled water $10.03 \mu \mathrm{g}$ $\mathrm{ml}^{-1}$ ). The stained flagellates were viewed in a Nikon inverted microscope at $600 \times$ magnification using a combination of UV and bright field.

Growth temperature experiments. In the growth experiments the initial cell concentration of both strains was adjusted to $10^{5}$ cells $\mathrm{ml}^{-1}$. These experiments used cultures of exponentially growing cells in $15 \mathrm{ml}$ screwcap plastic test tubes containing $10 \mathrm{ml}$ medium. The cultures were incubated upright with the caps screwed tightly on. Four different temperatures were tested: 5 to $20^{\circ} \mathrm{C}$, at $5^{\circ} \mathrm{C}$ increments. The tests were conducted in triplicate at 5,10 and $15^{\circ} \mathrm{C}$, but only in duplicate at $20^{\circ} \mathrm{C}$. The concentration of live trophozoites was deter- mined daily in sixty $0.0125 \mu$ subsamples from each test tube, using a haemocytometer and a Leitz light microscope at $100 \times$ magnification. The majority of the flagellates were concentrated as a visible mass at the bottom of the culture tubes, so before counting, the culture tubes were inverted gently until an even distribution of the cells was achieved. To ensure correct counting at high cell densities, the samples taken out for counting were diluted up to 40 times. The mean growth rate constant $k=\ln \left(N_{2} / N_{1}\right) /\left(t_{2}-t_{1}\right)$ was calculated for each strain and temperature in $3 \mathrm{~d}$ intervals (Day 0 to Day 3 after culture initiation, Day 1 to 4,2 to 5 and so on). $N_{1}$ and $N_{2}$ are the numbers of cells $\mathrm{ml}^{-1}$ at times $t_{1}$ and $t_{2}$ respectively. The highest $k$ value thus calculated was set as maximum $k$ for that specific strain and temperature. A mean minimum generation time $g=\ln 2 / k$ was then calculated for each strain and temperature. The entire experiment was repeated once.

\section{RESULTS}

\section{Light microscopy observations}

Actively swimming trophozoites rotated clockwise around their longitudinal axis. Binary longitudinal cell divisions were frequently seen. Some divisions resulted, however, in 2 cells of unequal size: a larger one with normal appearance, and a smaller one rotating rapidly around its longitudinal and transverse axis swimming without directional stability like older cells Frequently, large cells with 2 or more times the normal number of flagella were observed. Nucleic acid staining using DAPI showed that these were multinucleated cells having up to 10 nuclei (Fig. 1). Complete cytokinesis was never observed in these cells

\section{Temperature dependence}

Both strains were successfully cultivated at the 4 temperatures tested. Fig. 2 shows the temperaturedependent growth of the strains. In general, the grayling strain grew to higher densities than the salmon strain. This was most pronounced at 5 and $15^{\circ} \mathrm{C}$. The salmon strain reached its highest density at $10^{\circ} \mathrm{C}$. At $20^{\circ} \mathrm{C}$ the salmon strain was believed to be dead at Day 3, as no live flagellates could be seen in the samples taken for counting. The culture tubes were, however, checked again at Day 4 and, surprisingly, a low number of live flagellates could then be seen. This initiated a few days of intensive growth and the salmon strain reached almost the same cell density as the grayling strain, although a few days later. The 


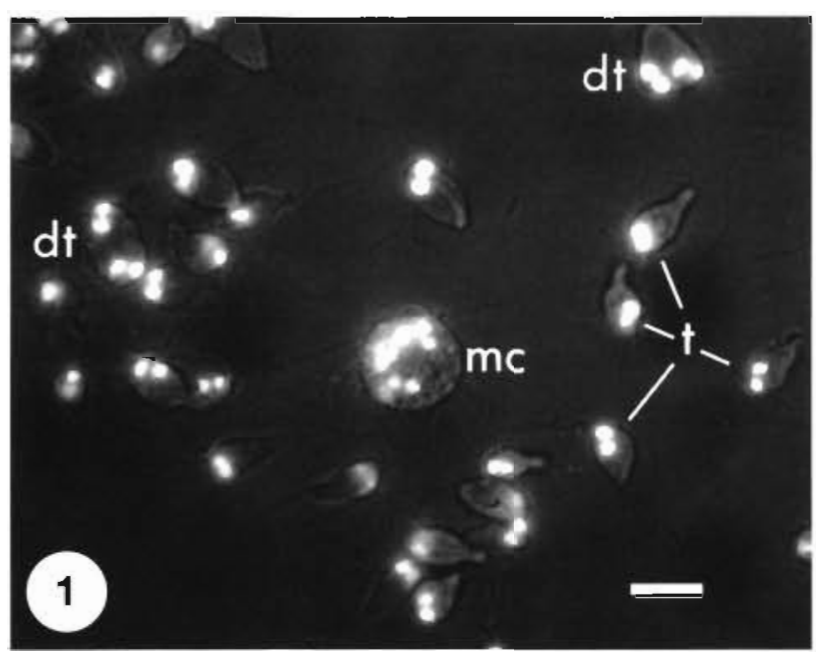

Fig. 1. Spironucleus barkhanus. Photomicrograph of trophozoites stained with 4'-6-diamidino-2-phenylindole and exposed to bright field and UV illumination. Nuclei appear white. t: trophozoites, dt: dividing trophozoite, mc: multinucleated cell. Scale bar $=10 \mu \mathrm{m}$

maximum yields, specific growth rate constants and generation times are summarised in Table 1.

In the repeated experiment the same results were achieved with 1 exception; the salmon strain did not grow at $20^{\circ} \mathrm{C}$. The cultures never recovered after the initial decline. After Day 4, no living trophozoites could be seen. Later attempts to cultivate the strain at $20^{\circ} \mathrm{C}$ also failed.

\section{DISCUSSION}

Keister's modified TYI-S-33 medium supported growth of Spironucleus barkhanus. Differences were not observed between cells obtained in vivo and in vitro based upon light microscopic observations, with 1 exception. The multinucleated cells have never been observed in vivo and could be a result of suboptimal growth conditions. The same phenomenon was observed in cultures of $S$. vortens (Poynton et al. 1995) and it was concluded to be an abnormality. Multiple division has been reported from Hexamita salmonis (Moore 1922, Davis 1926), but according to present

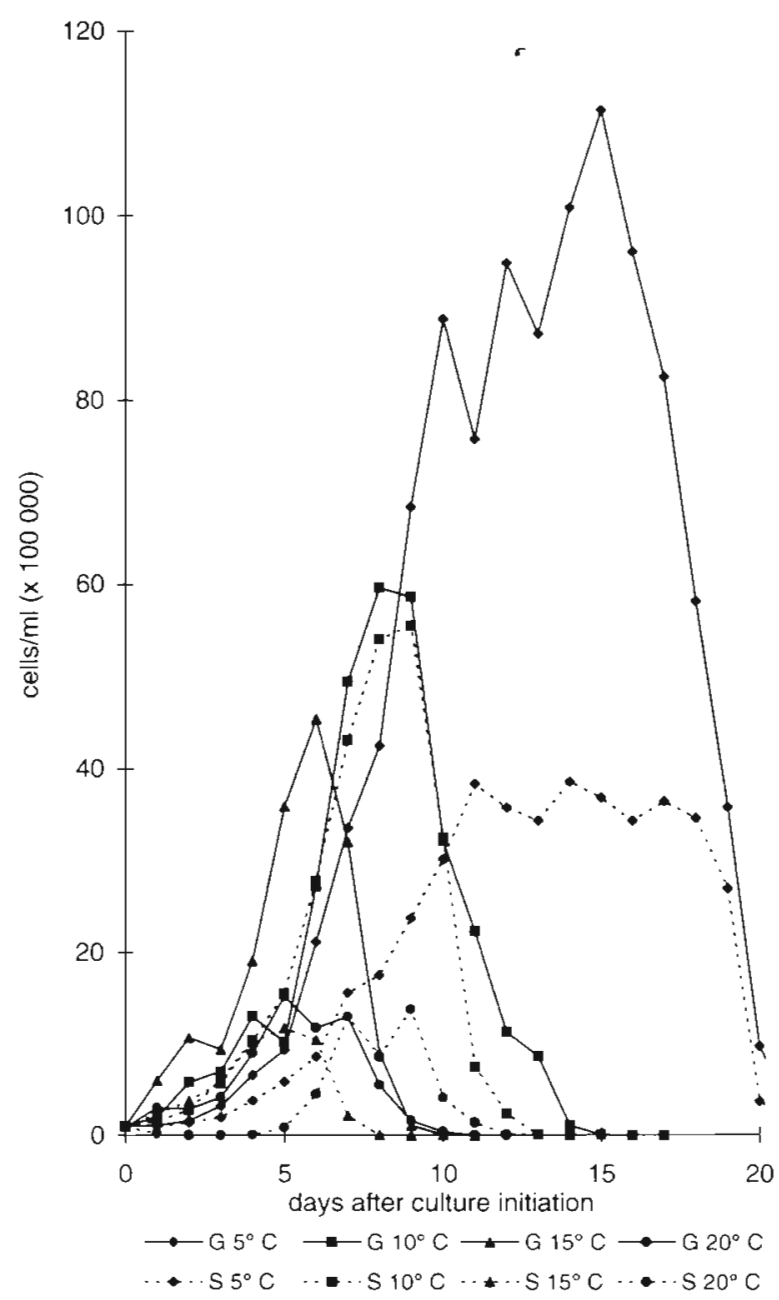

Fig. 2. Spironucleus barkhanus. Temperature-dependent population density in cultures of strains from grayling (G) and salmon (S). (Means of 3 replicates, 2 at $20^{\circ} \mathrm{C}$ )

knowledge $S$. barkhanus multiply only by longitudinal binary division. The observed unequal binary division resulting in one cell being greater than the other is considered to be a normal phenomenon.

Keister's medium is regarded as the medium of choice for cultivation of the genus Giardia (Kulda \& Nohynkova 1995). However, only certain strains of the G. duodenalis complex can be cultivated. According to

Table 1. Spironucleus barkhanus. Data on temperature-dependent in vitro growth of 2 strains. Values given are mean values of 3 replicates ( 2 replicates at $20^{\circ} \mathrm{C}$ )

\begin{tabular}{lcccccccc|}
\hline & \multicolumn{4}{c}{ Grayling strain } & \multicolumn{3}{c|}{ Salmon strain } \\
\hline Temperature $\left({ }^{\circ} \mathrm{C}\right)$ & 5 & 10 & 15 & 20 & 5 & 10 & 15 \\
Max. yield $\left(\right.$ cells ml ${ }^{-1}$ ) & $1.1 \times 10^{7}$ & $6.0 \times 10^{6}$ & $4.5 \times 10^{6}$ & $1.5 \times 10^{6}$ & $3.9 \times 10^{6}$ & $5.5 \times 10^{6}$ & $1.2 \times 10^{6}$ & $1.4 \times 10^{6}$ \\
Min. generation time $(\mathrm{h})$ & 26.5 & 26.5 & 22 & 30 & 34 & 26 & 28.5 & 8.5 \\
Growth rate constant & 0.63 & 0.62 & 0.75 & 0.56 & 0.49 & 0.64 & 0.58 & 1.94 \\
\hline
\end{tabular}


Faubert \& Belosevic (1990) G. muris cannot be cultured in vitro, and, to the best of my knowledge, in vitro cultivation of $G$. agilis has never been reported. It is therefore most interesting that Keister's medium is well suited for cultivation of Spironucleus barkhanus, and also $S$. vortens as reported by Poynton et al. (1995). However, Keister's medium failed to support growth of Hexamita salmonis (Buchmann \& Uldal 1996), which is more closely related to the genus Spironucleus than Giardia spp. are. There are obvious physiological differences between diplomonad species, but apparently not all these differences follow generic lineages. The present results indicate that there must be some basic properties of TYI-S-33 medium that can meet the demands of species of different diplomonad genera, and perhaps only small alterations in the medium are needed to succeed in culturing other species.

Spironucleus barkhanus seems to be able to live and multiply at high densities. A cell density of more than $10^{7}$ cells $\mathrm{ml}^{-1}$ in culture is 5 times higher than reported for Giardia lamblia (Visvesvara 1980, Keister 1983) and 40 times higher than reported for Hexamita salmonis (Uzmann \& Hayduk 1963, Buchmann \& Uldal 1996). This could reflect the suitability of the medium for $S$. barkhanus, but a potential for high reproductive activity was also seen in vivo in the salmon suffering from systemic spironucleosis, where large muscle abscesses were found to contain a high density of trophozoites in pure culture (Poppe et al. 1992).

It has been common practice when cultivating diplomonads to add antibiotics to the medium (Uzmann \& Hayduk 1963, Radulescu \& Meyer 1990, Poynton et al. 1995, Buchmann \& Uldal 1996). The flagellate strains used in the present study have been continously cultivated for more than a year without any kind of antibiotic supplementation. It was found to be of vital importance that the flagellates were isolated immediately after the host fish was killed, as bacteria invaded the gall bladder a short time after the death of the fish. Cultures based on flagellates isolated from the gall bladder of fish that had been dead for some time were contaminated with bacteria, and flagellate growth did not persist more than a month. The same was seen in cultures established with flagellates isolated from the intestine.

As perhaps would be expected of an endoparasite of poikilothermic animals living in an environment with substantial annual temperature variation, the present results show that Spironucleus barkhanus is eurythermic. However, there seemed to be some differences between the 2 strains. The absolute shortest generation time observed in the experiments was seen in the salmon strain at $20^{\circ} \mathrm{C}$. Nevertheless it is believed that the grayling strain has a slightly higher temperature limit, as this strain could be repeatedly cultivated at $20^{\circ} \mathrm{C}$, while the salmon strain failed to grow at this temperature in repeated experiments. $20^{\circ} \mathrm{C}$ is, therefore, regarded as the absolutc upper temperature limit of the salmon strain and the low generation time seen once cannot be regarded as a constant feature of the strain at this temperature. The lower generation time seen in the grayling strain at $5^{\circ} \mathrm{C}$ also indicates that the eurythermy is slightly more pronounced in this strain. When considering the optimum temperatures of the 2 strains, one should also look at the generation times in Table 1 . These indicate that $15^{\circ} \mathrm{C}$ is the optimum temperature for the grayling strain and $10^{\circ} \mathrm{C}$ is the optimum for the salmon strain (if one ignores the perhaps accidentally low generation time at $20^{\circ} \mathrm{C}$, as mentioned above). These optimum temperatures are not readily seen from the growth curves presented in Fig. 2. It could be tempting from these curves to consider $5^{\circ} \mathrm{C}$ as the optimum temperature for the grayling strain, giving by far the highest yield. It is important though to remember that this is an in vitro situation in which, after some time, there will be a deficiency of nutrients and a high concentration of metabolites. The death of the cultures is probably a result of both these factors. In vivo there is a constant renewing of the 'growth medium', and the optimum temperature is the one giving the fastest exponential growth (shortest generation time).

The different temperature responses seen in the 2 strains is not incompatible with the conclusions of Sterud et al. (1997) that these strains are the same species. Different temperature responses between races/clones of a single species is well known in freeliving protists, and no single clone or strain should be considered to be representative of an entire species (Granskog 1991). Such physiological features as temperature tolerance, salinity tolerance, etc. have been shown to be genetically determined (Brand 1981). The different temperature-dependent growth of the 2 strains in the present study may reflect their adaptation to different thermal environments. In the river Glomma, where the grayling was caught, the annual temperature range is wider and the annual mean temperature higher than in the waters of northern Norway where the salmon was farmed. The higher optimum temperature and also the higher temperature limit of the grayling strain is in agreement with this hypothesis.

Acknowledgements. I wish to thank Dr Thomas A. Nerad for cooperation on the cultivation of the, by then, 'Hexamita sp.' causing systemic disease in salmon. Thanks to Dr Dag Klaveness for guidance in the use of DAPI, and for valuable comments on the manuscript. Drs Trygve T Poppe, Tor Atle Mo and Chris Appleby have all assisted during field work, and Dr Poppe also kindly revised the manuscript. 


\section{LITERATURE CITED}

Bassleer G (1983) Disease prevention and control. Freshwat Mar Aquar Mag 6:38-41,58-60

Brand LE (1981) Genetic variability in reproduction rates in marine phytoplankton populations. Evolution 35:1117-1127

Buchmann K, Uldal A (1996) Temperature, pH and bile dependent in vitro cultivation of Hexamita salmonis from rainbow trout Oncorhynchus mykiss intestine. Dis Aquat Org 24:169-172

Davis HS (1926) Octomitus salmonis, a parasitic flagellate of trout. Bull Bur Fish Wash 42:9-26

Diamond LS, Harlow DR, Cunnick CC (1978) A new medium for the axenic cultivation of Entamoeba histolytica and other Entamoeba. Trans R Soc Trop Med Hyg 72 : 431-432

Granskog LM (1991) Growth rate variations in 17 Skeletonema costatum (Grev.) Cleve strains from Norwegian coastal waters. Thesis, University of Trondheim

Guillard RRL, Lorenzen CJ (1972) Yellow-green algae with chlorophyllide $\mathrm{C}^{\mathrm{L}, 2}$. J Phycol 8:10-14

Faubert GM, Belosevic M (1990) Animal models for Giardia duodenalis type organisms. In: Meyer EA (ed) Giardiasis. Elsevier, Amsterdam, p 77-90

Ferguson HW, Moccia RD (1980) Disseminated hexamitiasis in Siamese fighting fish. J Am Vet Med Assoc 177:854-857

Keister DB (1983) Axenic culture of Giardia lamblia in TYI-S33 medium supplemented with bile. Trans R Soc Trop Med Hyg 77:487-488

Kent ML, Ellis J, Fournie JW, Dawe SC, Bagshaw JW, Whitaker DJ (1992) Systemic hexamitid (Protozoa: Diplomonadida) infection in seawater pen-reared chinook salmon Oncorhynchus tshawytscha. Dis Aquat Org 14:81-89

Kulda J, Nohynkova E (1995) Giardia in humans and animals. In: Kreier JP (ed) Parasitic Protozoa, Vol 10, 2nd edn. Academic Press Inc, San Diego, p 225-422

Editorial responsibility: Wolfgang Körting,

Hannover, Germany
Miura S, Oshima K (1960) On octomitiasis in rainbow trout with special reference to the pathological findings. Jpn J Vet Sci 22:201-208

Moore E (1922) Octomitus salmonis, a new species of intestinal parasite in trout. Trans Am Fish Soc 52:74-97

Poppe TT, Mo TA (1993) Systemic, granulomatous hexamitosis of farmed Atlantic salmon: interaction with wild fish. Fish Res 17:147-152

Poppe TT, Mo TA, Iversen L (1992) Disseminated hexamitosis in sea-caged Atlantic salmon Salmo salar. Dis Aquat Org 14:91-97

Poynton SL, Fraser W, Francis-Floyd R, Rutledge P, Reed P, Nerad TA (1995) Spironucleus vortens n. sp. from the freshwater angelfish Pterophyllum scalare: morphology and culture. J Eukaryot Microbiol 42:731-742

Radulescu S, Meyer EA (1990) In vitro cultivation of Giardia trophozoites. In: Meyer EA (ed) Giardiasis. Elsevier, Amsterdam, p 99-110

Sano $T(1970)$ Etiology and histopathology of hexamitiasis and an IPN-like disease of rainbow trout. J Tokyo Univ Fish 56:23-30

Sterud E, Mo TA, Poppe TT (1997) Ultrastructure of Spironucleus barkhanus $\mathrm{n}$. sp. (Diplomonadida: Hexamitidae) from grayling Thymallus thymallus (L.) (Salmonidae) and Atlantic salmon Salmo salar L. (Salmonidae). J Eukaryot Microbiol 44:399-407

Uzmann JR, Hayduk SH (1963) In vitro culture of the flagellate protozoan Hexamita salmonis. Science 140:290-291

Visvesvara GS (1980) Axenic growth of Giardia lamblia in Diamond's TPS-1 medium. Trans R Soc Trop Med Hyg 74: $213-215$

Woo PTK, Poynton SL (1995) Diplomonadida, Kinetoplastida and Amoebida (Phylum Sarcomastigophora). In: Woo PTK (ed) Fish diseases and disorders, Vol 1 Protozoan and metazoan infections. $C A B$ International, Wallingford, p $27-96$

Submitted: October 20, 1997; Accepted: March 3, 1998 Proofs received from author(s): April 29, 1998 